\title{
Removal of arsenic (V) from aqueous solutions using chemically modified sawdust of spruce (Picea abies): Kinetics and isotherm studies
}

\author{
${ }^{1 *}$ M. Urík; ${ }^{1}$ P. Littera; ${ }^{1} \mathrm{~J}$. Ševc; ${ }^{1} M$. Kolenčik; ${ }^{2}$ S. Čerňanský \\ ${ }^{1}$ Institute of Geology, Faculty of Natural Sciences, Comenius University in Bratislava, Mlynská dolina, \\ Bratislava, Slovakia \\ ${ }^{2}$ Department of Ecosozology and Physiotactics, Faculty of Natural Sciences, Comenius University in Bratislava, \\ Mlynská dolina, Bratislava, Slovakia \\ Received 18 March 2009; $\quad$ revised 21 April 2009; accepted 6 May 2009; available online 1 June 2009
}

\begin{abstract}
Arsenic is a ubiquitous element in the environment and occurs naturally in both organic and inorganic forms. Under aerobic condition, the dominant form of arsenic in waters is arsenate, which is highly mobile and toxic. Arsenic poisoning from drinking water remains a serious world health issue. There are various standard methods for arsenic removal from drinking waters (coagulation, sorption, ion-exchange reactions or methods of reverse osmosis) and alternative methods, such as biosorption. Biosorption of arsenic from natural and model waters by native or chemically modified (with urea or ferric oxyhydroxides) plant biomass prepared from sawdust of Picea abies was studied. The kinetic of the adsorption process fitted well the pseudo second order adsorption model and equilibrium was achieved after $2 \mathrm{~h}$. The results showed that biosorption was well described by both Langmuir and Freundlich isotherms. The maximum biosorption capacity of the sawdust modified with ferric oxyhydroxides, evaluated by Langmuir adsorption model, was $9.259 \mathrm{mg} / \mathrm{g}$, while the biosorption capacity of unmodified biosorbent or biosorbent modified with urea was negligible. The adsorption capacity is comparable to results published by other authors, suggesting that the prepared chemically modified biosorbent has potential in remediation of contaminated waters.
\end{abstract}

Keywords: Adsorption; Bioremediation; Biosorption; Plant biomass

\section{INTRODUCTION}

Arsenic compounds are common contaminants in the environment. Because of arsenic toxicity and induced carcinogenity (Eblin et al., 2006; Hughes, 2002), higher arsenic concentration in the environment represents serious problems for human health, especially for populations in Bangladesh, Western Bengal, Vietnam, China, Mexico and Chile. The danger of elevated arsenic concentration in waters in these countries was underlined by WHO, which estimated the recommended limit for arsenic concentration in drinking waters up to $10 \mu \mathrm{g} / \mathrm{L}$ (WHO, 1996). The conventional technologies for arsenic removal from waters are based on processes of coagulation, sorption, ion-exchange reactions or methods of reverse osmosis. Materials used in these processes are $\mathrm{Fe}$ (0), $\mathrm{Fe}$ (III) oxyhydroxides, $\mathrm{Mn}$ (II), $\mathrm{Al}$ (III), apatite, silicate sands, carbonates, sulphides, ash or various types of coal (Chmielewská et al., 2008; Daus

\*Corresponding Author Email: urik@fns.uniba.sk

Tel./Fax: +4212 60296392 et al., 2004; DeMarco et al., 2003; Hiller et al., 2007; Lin and Wu, 2001; Sato et al., 2002; Song et al., 2006). Nowadays, there is a trend to use the alternative and low-cost materials for arsenic removal from the waters in laboratory or medium-scale experiments. Effectiveness of chemically modified or native biomass in processes of arsenic removal was evaluated and proved by various authors (Abdel-Ghani et al., 2007; Boddu et al., 2008; Cernansky et al., 2007; Loukidou et al., 2003; Malakootian et al., 2009; Murugesan et al., 2006; Rahaman et al., 2008; Seki et al., 2005).

The aim of this study was to evaluate effectiveness of chemically modified with $\mathrm{Fe}$ (III) or urea or unmodified plant biomass prepared from sawdust of Picea abies to remove arsenic from model or natural arsenic contaminated water. The influence of various initial arsenic concentrations was also tested and the kinetics of the adsorption process was evaluated. This experiment was realized in the laboratories of the 
Institute of Geology (Bratislava, Slovakia) on September and December 2008.

\section{MATERIALS AND METHODS}

Preparation of biosorbents

The plant biomass was prepared from sawdust of Picea abies (160 €/t of biomass). The sawdust was washed with great amount of deionized water, sieved and part of fraction under $0.2 \mathrm{~mm}$ was used in the experiments as chemically unmodified biosorbent. The other part of fraction was used to prepare biosorbents modified with urea and ferric Fe (III) oxyhydroxides. To prepare Fe (III) modified biomass, the sawdust fraction was homogenized with a mixture of prepared iron oxyhydroxide and $\mathrm{NaOH}$ solution and dried in the oven overnight according to procedure proposed by Pokhrel and Viraraghavan (2006). To prepare biosorbent modified with urea, the sawdust fraction (10 g) was agitated (140 $\mathrm{rpm})$ in the presence of urea (200 g/L) for $24 \mathrm{~h}$, then rinsed with deionized water and dried in oven $\left(80^{\circ} \mathrm{C}\right)$ overnight. The third chemical modification was a combination of previous two procedures, when the sawdust fraction was coated with Fe (III) oxyhydroxides in the presence of urea.

\section{Biosorption of arsenic from natural waters}

The natural water contaminated with arsenic (concentration of total arsenic was $230 \mu \mathrm{g} / \mathrm{L}$ ) was collected from Poša (Eastern Slovakia). The volume of $50 \mathrm{ml}$ of contaminated water was transferred into $250 \mathrm{~mL}$ beaker and $1 \mathrm{~g}$ of native or chemically modified biosorbent prepared from sawdust was added. The system was agitated at $140 \mathrm{rpm}$ for $2 \mathrm{~h}$. The agitation time was selected according to preliminary and kinetic studies, since $2 \mathrm{~h}$ were required to reach equilibrium. After $2 \mathrm{~h}$, the biosorbent was separated by filtration, washed with deionized water and then the amount of arsenic in residual solution was measured. Dry weight of biosorbent was measured after drying at $105^{\circ} \mathrm{C}$. All the experiments were carried out in triplicates.

\section{Kinetic and equilibrium adsorption experiments}

The stock solution was prepared by dissolution of arsenic species $\mathrm{Na}_{2} \mathrm{HAsO}_{4}$ (Merck, Germany) in distilled water. The initial concentrations of As (V) in prepared model solutions varied from 20 up to $500 \mathrm{mg} / \mathrm{L}$. The $\mathrm{pH}$ value was adjusted to 8 ( $\mathrm{pH}$ value, when all of $\mathrm{As}(\mathrm{V})$ in solution is ionized) using the solution of $1 \mathrm{M} \mathrm{NaOH}$. 0.5 $\mathrm{g}$ of chemically modified or unmodified biosorbent was then transferred into the $50 \mathrm{~mL}$ solution with desired As (V) concentration and agitated on rotatory shaker (Unimax 2100, Heidolph, Germany) at $140 \mathrm{rpm}$. After desired time (15 to $240 \mathrm{~min}$ ) the biosorbents were separated from solution by filtration. Arsenic in solution was then stabilized with concentrated $\mathrm{HCl}$ and the amount of total arsenic was determined. Dry weight of biomass was measured after drying at $105^{\circ} \mathrm{C}$. All the experiments were carried out in triplicates.

\section{Experimental data analysis}

The experimental data were analyzed using Freundlich (1906) and Langmuir (1918) adsorption isotherms and pseudo first and pseudo second order kinetic model. The linear equations of isotherm and kinetic models were used to gain appropriate constants and to evaluate experimental data.

Linear Freundlich equation was used as:

$\log S_{e q}=\log K_{F}+N \log C_{e q}$

Where, $K_{F}$ and $N$ are the Freundlich constants. $K_{F}$ is the indicator for adsorption capacity of the adsorbent when the concentration of adsorbate at equilibrium is unitary. $N$ represents the heterogeneity factor, which characterizes surface with energetically nonequivalent sites.

Linear Langmuir equation was used as:

$$
\frac{C_{e q}}{S_{e q}}=\frac{1}{k S_{m}}+\frac{C_{e q}}{S_{m}}
$$

Where, $S_{m}$ is the maximum adsorption capacity corresponding to complete monolayer coverage (mg/ g) and $k$ is the Langmuir constant that relates to the energy of adsorption (L/mg). $C_{e q}$ represents equilibrium concentration of As $(\mathrm{V})$ in solution $(\mathrm{mg} / \mathrm{L})$ and $S_{\text {eq }}$ amount of As (V) adsorbed onto biomass at equilibrium concentration (mg/g).

By integrating and applying the boundary conditions ( $t=t$ and $S_{t}=S_{e q}$ ) to the pseudo first order rate expression of Lagergren (1889), the original expression may be described by the following equation:

$$
\ln \left(\frac{S_{e q}-S_{t}}{S_{t}}\right)=-k_{1} t
$$

Where, $k_{1}$ is the pseudo first order kinetic constant (1/min) and $S_{t}$ represent adsorption capacity (mg/g) of 
biosorbent at time $t$ (min).

According to Ho and McKey (1999), the linearized form of pseudo second order rate expression was used as:

$\frac{t}{S_{t}}=\frac{t}{S_{e q}}+\frac{1}{k_{2} S_{e q}^{2}}$

Where, $\mathrm{k}_{2}$ represent pseudo second rate constant (g/mg/min).

\section{Analytical procedures}

For the determination of total arsenic in samples, a laboratory electrochemical analyser EcaFlow 150 (Istran, Bratislava, Slovakia) was used, which applies flow-through electrochemical coulometry and inelectrode coulometric titrations.

\section{RESULTS AND DISCUSSION}

Arsenic removal efficiency by adsorbents from natural water

The As (V) removal efficiency from natural waters contaminated with arsenic $(0.230 \mathrm{mg} / \mathrm{L})$ by four different biosorbents was compared using the batch-wise method. The most effective adsorbent was the Fe(III) modified sawdust (Fig. 1), which removed nearly $100 \%$ of arsenic. The Fe (III) oxyhydorxide modification of biosorbent was also successfully applied in other studies (Pokhrel and Viraraghavan, 2008). The application of chemical treatment with urea was based on assumption, that urea should create new adsorption positions. Apparently,

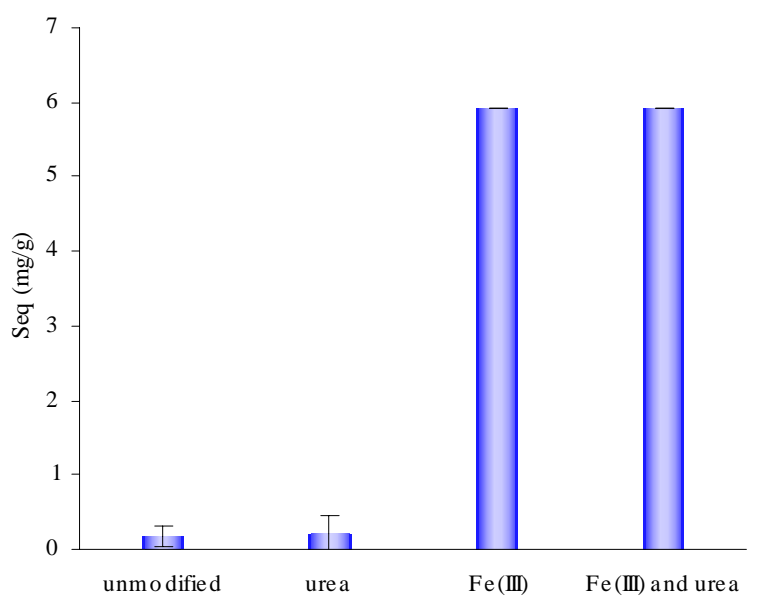

Type of chemical mo dification

Fig. 1: The effect of chemical modification on the adsorption capacity of sawdust prepared from spruce (Picea abies) for removal of arsenic $(0.230 \mathrm{mg} / \mathrm{L})$ from natural contaminated water adsorption capacity decreased after modification of unmodified or Fe (III) modified biomass, assuming diverse effect had taken place, probably revealing the complexation activity of urea as an chelating agent that occupies the adsorption positions on the adsorbent surface. The adsorption capacity of chemically unmodified biomass was negligible (Fig. 1). Hence, it is assumed that only iron is responsible for $\mathrm{As}(\mathrm{V})$ removal and spruce sawdust is only enhancing the mechanical properties of the prepared hybrid adsorbent. Therefore, the Fe (III) modified adsorbent was used in following kinetic and equilibrium experiments.

\section{Kinetic experiments}

Fig. 2 shows that within the first 60 min a rapid uptake of As (V) takes place. After this time, the rate of As (V) uptake was reduced as the equilibrium approached. The equilibrium for As (V) bisorption onto modified sawdust was reached after $120 \mathrm{~min}$. Therefore, this time was chosen for further batch adsorption experiments. The experimental data presented in Fig. 2 could be fitted well for the pseudo first $\left(r^{2}=0.968\right)$ and pseudo second $\left(r^{2}=\right.$ 0.984 ) order model of adsorption rate. However, the best adjustment was observed for the pseudo second order kinetic, which is based on the assumption that rate limiting step is chemisorption (Ho, 2006). According to work of Goldberg and Johnston (2001), the mechanism of As (V) adsorption onto amorphous oxides seems to be formation of inner and outer sphere surface complexes. Thus, the formation of chemical bound is involved. The calculated value of pseudo second order rate constant was $0.012 \mathrm{~g} / \mathrm{mg} / \mathrm{min}$ However, the pseudo second kinetic model may not indicate the diffusion mechanism, which is essentially associated with adsorption. Hence, the integrated intraparticle diffusion model developed by Weber and Morris (1963) was used to explore the possibility of intraparticle diffusion resistance affecting the adsorption. The model was used as:

$S_{t}=K_{i} t^{1 / 2}+C$

Where, $K_{i}$ is the diffusion rate constant ( $\mathrm{mg} / \mathrm{g} / \mathrm{min}$ ) and value of $C(\mathrm{mg} / \mathrm{g})$ is proportional to boundary layer thickness (Kannan and Sundaram, 2001). It has been reported that the adsorption capacity decreases when the thickness of boundary layer decreases (Aksu, 2001). If the plot of adsorption capacity $\left(S_{t}\right)$ versus the square root of time is linear, the intra particle diffusion is involved and if the line passes through the origin, diffusion in the biosorbent is the only controlling step. However, only within the first $100 \mathrm{~min}$ the plot presented 


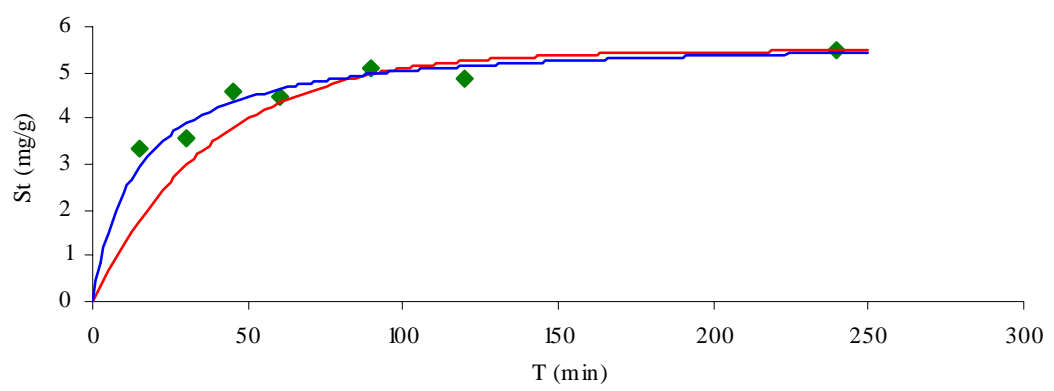

- experimentaldata — pseudo first order kinetic model — pseudo second order kinetic model

Fig. 2: Pseudo first and pseudo second kinetic models of As (V) adsorption onto sawdust chemically modified with Fe (III) oxyhydroxides (initial concentration of As (V) was $90 \mathrm{mg} / \mathrm{L}$ )

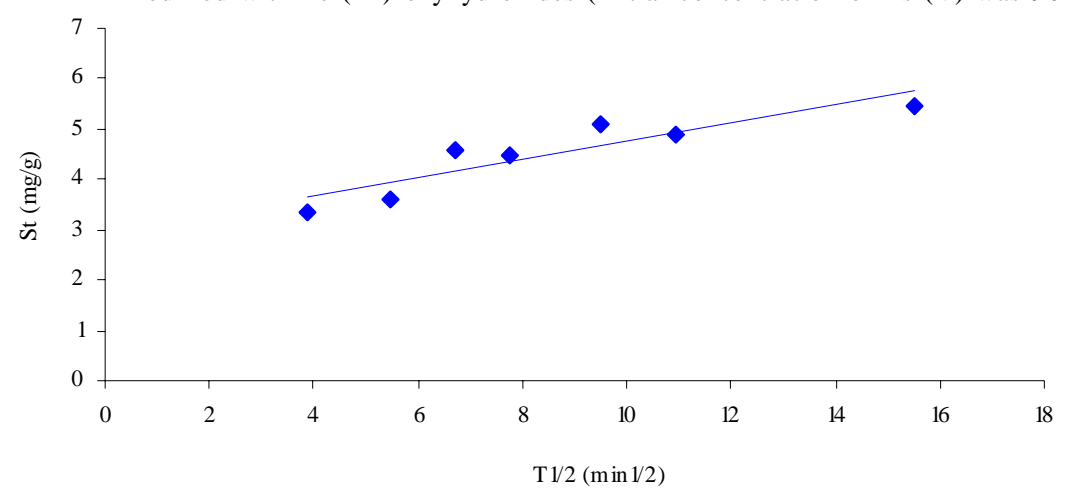

Fig. 3: Intraparticle diffusion model (initial concentration of As (V) was $90 \mathrm{mg} / \mathrm{L}$ )

in Fig. 3 shows relevant linearity $\left(\mathrm{r}^{2}=0.917\right)$ and the intercept $(C)$ has higher value than zero (2.037). Therefore, some boundary layer control must be involved and intraparticle diffusion is not the rate limiting factor.

\section{Adsorption isotherms}

The experimental data for As (V) removal from aqueous solution were analyzed using Langmuir and Freundlich equilibrium isotherm models. The evaluation of the correlation between experimental data and equilibrium models is important for design of the most appropriate adsorption system for As (V) removal. The adjustable constants for Langmuir and Freundlich equations are presented in Table. 1. The Freundlich equation predicts that the adsorption capacities for the adsorbate will increase as long as there is an increase in the adsorbate concentration. The experimental results follow well Freundlich model $\left(r^{2}=0.968\right)$. However, the adsorption capacity of the spruce sawdust modified with Fe (III) resulted to plateau within experimental concentration range of As (V) (Fig. 4). Hence, the correlation coefficient for Langmuir isotherm is higher $\left(r^{2}=0.984\right)$. Therefore it is assumed that limited adsorption capacity of the adsorbent up to $S_{\text {max }}(9.86 \mathrm{mg} / \mathrm{g})$, which is comparable with other related studies using ferric modified organic adsorbents or inorganic reagents (Lorenzen et al., 1995; Singh et al., 1996). However, the adsorption capacity is lower when compared to biomass modified with cationic polyelectrolyte (Loukidou et al., 2003). The mechanism of As (V) adsorption on the surface of amorphous Fe (III) oxyhidroxides involves both inner and outer sphere complexation (Goldberg and Johnston, 2001; Jonsson and Sherman, 2008). That implies heterogenous adsorption sites that have different energy and may explain the high correlation coefficient of Freundlich equilibrium model.

The Freundlich equation parameter should also be used as a relative measure of the adsorption capacity when the concentration of As (V) is unitary. At equilibrium concentration of $1 \mathrm{mg} / \mathrm{L}$ of As (V), $1 \mathrm{~g}$ of prepared hybrid adsorbent removed $1.369 \mathrm{mg}$ of arsenic from solution. It have been observed a slight decrease of $\mathrm{pH}$ of the bulk solution during the kinetic and equilibrium adsorption experiments (from 8 to 7.6). The comparison of $\mathrm{pH}$ value in arsenic solutions before and after the adsorption experiment confirmed the 


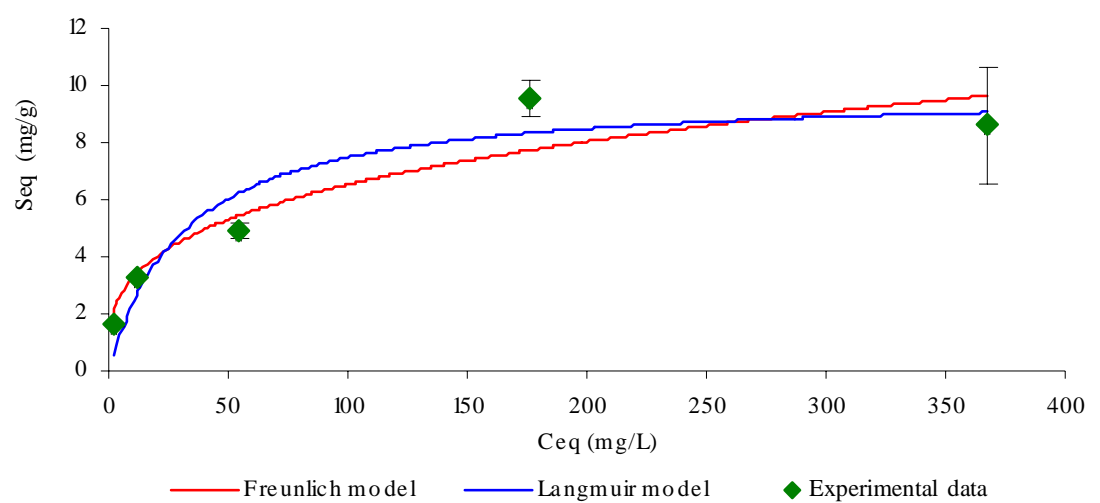

Fig. 4: Langmuir and Freundlich model of As (V) adsorption onto sawdust chemically modified with Fe (III) oxyhydroxides

Table 1: Adjustable parameters and correlation coefficients for Langmuir and Freundlich isotherms calculated from experimental data of As (V) adsorption onto sawdust prepared from spruce (Picea abies) coated with Fe (III) oxyhydorxides

\begin{tabular}{llllll}
\hline \multicolumn{2}{l}{ Langmuir isotherm constants } & \multicolumn{3}{l}{ Freundlich isotherm constants } \\
\hline$S_{m}$ & $k$ & $r^{2}$ & $K_{F}$, & $N$ & $r^{2}$ \\
9.259 & 0.049 & 0.984 & 1.369 & 0.336 & 0.968 \\
\hline
\end{tabular}

$S_{m}$, maximum uptake capacity of the adsorbent $(\mathrm{mg} / \mathrm{g}) ; k$, Langmuir binding constant; $K_{F}$, adsorption capacity when the concentration of the metal ion in equilibrium is unitary; $N$, Freundlich constant related to the adsorption intensity

observation of Mamisahebei et al. (2007), who observed the slight increase in concentration of $\mathrm{H}^{+}$in solution after biosorption. The decrease of $\mathrm{pH}$ value was probably resulting from mechanism of As (V) adsorption onto the surface of adsorbent.

\section{CONCLUSION}

The major conclusions based on the experimental study were:

1. Adsorbent prepared by chemical modification of spruce (Picea abies) using Fe (III) oxyhydroxide showed high affinity for As (V). The adsorption experiments revealed its possible application for arsenic removal from natural contaminated waters;

2. The adsorption kinetic data were well described by both pseudo first and pseudo second order rate expressions. However, the correlation coefficient was more adjustable for pseudo second model, assuming chemisorptions as the uptake mechanism. Intraparticle diffusion was not proved as a possible rate limiting step of arsenic removal and

3. The maximum adsorption capacity of Fe(III) modified sawdust was $9.259 \mathrm{mg} / \mathrm{g}$. However, the experimental data fitted well both Langmuir and Freundlich isotherm models.

\section{ACKNOWLEDGEMENTS}

This work was financially supported by UK 216/ 2009 and VEGA 1/4361/07.

\section{REFERENCES}

Abdel-Ghani, N. T.; Hefny, M.; El-Chagbaby, G. A. F., (2007). Removal of lead from aqueous solution using low cost abundantly available adsorbents. Int. J. Environ. Sci. Tech., 4 (1), 67-73 (7 pages).

Aksu, Z., (2001). Equilibrium and kinetic modeling of cadmium (II) biosorption by C. vulgaris in a batch system: Effect of temperature. Sep. Purif. Tech., 21 (3), 285-294 (10 pages).

Boddu, V. M.; Abburi, K.; Talbott, J. L.; Smith, E. D.; Haasch, R., (2008). Removal of arsenic (III) and arsenic (V) from aqueous medium using chitosan-coated biosorbent. Water Res., 42 (3), 633-642 (10 pages).

Cernansky, S.; Urík, M.; Ševc, J.; Hiller, E., (2007). Biosorption of arsenic and cadmium from aqueous solutions. Afr. J. Biotechnol., 6 (16), 1932-1934 (3 pages).

Chmielewská, E.; Sabová, L.; Jesenák, K., (2008). Study of adsorption phenomena ongoing onto clinoptilolite with the immobilized interfaces. J. Therm. Anal. Calorim., 92 (2), 567-571 (5 pages).

Daus, B.; Wennrich, R.; Weiss, H., (2004). Sorption materials for arsenic removal from water: A comparative study. Water Res., 38 (12), 2948-2954 (7 pages).

DeMarco, M. J.; SenGupta, A. K.; Greenleaf, J. E., (2003). Arsenic removal using a polymeric/inorganic hybrid sorbent. Water Res., 37 (1), 164-176 (13 pages).

Eblin, K. E.; Bowen, M. E.; Cromey, D. W.; Bredfeldt, T. G.; Mash, E. A.; Lau, S. S.; Gandolfi, A. J., (2006). Arsenite and monomethylarsonous acid generate oxidative stress response in human bladder cell culture. Toxicol. Appl. Pharm., 217 (1), 7-14 (8 pages).

Freundlich, H., (1906). Über die adsorption in lősungen. Z. Phys. Chem., 57, 384-470 (7 pages).

Goldberg, S.; Johnston, C. T., (2001). Mechanism of arsenic adsorption on amorphous oxides evaluated using macroscopic 
measurements, vibrational spectroscopy, and surface complexation modeling. J. Colloid. Interf. Sci., 234 (1), 204216 (13 pages).

Hiller, E.; Veselská, V.; Majzlan, J., (2007). Arsenic mobility in stream sediments and impoundment material as evaluated by column and batch experiments. J. Hydrol. Hydromech., 55 (4), 223-235 (13 pages).

Ho, Y. S., (2006). Second-order kinetic model for the sorption of cadmium onto tree fern: A comparison of linear and nonlinear methods. Water Res., 40 (1), 119-125 (7 pages).

Ho, Y. S.; McKey, G., (1999). Pseudo-second order model for sorption processes. Proc. Biochem., 34 (5), 451-465 (15 pages)

Hughes, M. F., (2002). Arsenic toxicity and potential mechanisms of action. Toxicol. Lett., 133 (1), 1-16 (16 pages).

Jonsson, J.; Sherman, D. M., (2008). Sorption of As (III) and As (V) to siderite, green rust (fougerite) and magnetite: Implications for arsenic release in anoxic groundwaters. Chem. Geol., 255 (1-2), 173-181 (9 pages).

Kannan, N.; Sundaram, M. M., (2001). Kinetics and mechanism of removal of methylene blue by adsorption on various carbons: A comparative study. Dyes Pigments, 51 (1), 25-40 (16 pages).

Lagergren, S., (1889). Zur theorie der sogenannten adsorption gelöster stoffe. Kungliga Svenska Vetenskapsakademiens. Handlingar, 24, 1-39 (39 pages).

Langmuir, I., (1918). The adsorption of gases on plane surfaces of glass, mica, and platinum. J. Am. Chem. Soc., 40 (9), 1361-1403 (43 pages).

Lin, T.; Wu, J., (2001). Adsorption of arsenite and arsenate within activated alumina grains: Equilibrium and kinetics. Water Res., 35 (8), 2049-2057 (9 pages).

Lorenzen, L.; van Deventer, J. S. J.; Landi, W. M., (1995). Factor affecting the mechanism of the adsorption of arsenic species on activated carbon. Miner. Eng., 8 (4-5), 557-569 (13 pages)

Loukidou, M. X.; Matis, K. A.; Zouboulis, A. I.; LiakopoulouKyriakido, M., (2003). Removal of As (V) from wastewaters by chemically modified fungal biomass. Water Res., 37 (18), 4544-4552 (9 pages).

Malakootian, M.; Nouri, J.; Hossaini, H., (2009). Removal of heavy metals from paint industries wastewater using Leca as an available adsorbent. Int. J. Environ. Sci. Tech., 6 (2), 183190 (8 pages)

Mamisahebei, S.; Jahed Khaniki, G. R.; Torabian, A.; Nasseri, S.; Naddafi, K., (2007). Removal of arsenic from aqueous solution by pretreated waste tea fungal biomass. Iran J. Environ. Health Sci. Eng., 4 (2), 85-92 (8 pages).

Murugesan, G. S.; Sathishkumar, M.; Swaminathan, K., (2006). Arsenic removal from groundwater by pretreated waste tea fungal biomass. Bioresource Technol., 97 (3), 483-487 (5 pages).

Pokhrel, D.; Viraraghavan, T., (2006). Arsenic removal from an aqueous solution by a modified fungal biomass. Water Res., 40 (3), 549-552 (4 pages).

Pokhrel, D.; Viraraghavan, T., (2008). Arsenic removal from an aqueous solution by modified $A$. niger biomass: Batch kinetic and isotherm studies. J. Hazard Mater., 150 (3), 818825 (8 pages).

Rahaman, M. S.; Basu, A.; Islam, M. R., (2008). The removal of As (III) and As (V) from aqueous solutions by waste materials. Bioresource Technol., 99 (8), 2815-2823 (9 pages).

Sato, Y.; Kang, M.; Kamei, T.; Magara, Y., (2002). Performance of nanofiltration for arsenic removal. Water Res., 36 (13), 3371-3377 (7 pages).

Seki, H.; Suzuki, A.; Maruyama, H., (2005). Biosorption of chromium (VI) and arsenic (V) onto methylated yeast biomass. J. Colloid. Interf. Sci., 281 (2), 261-266 (6 pages).

Singh, D. B.; Prasad, G.; Rupainwar, D. C., (1996). Adsorption technique for the treatment of As (V)-rich effluents. Colloid. Surface. A, 111 (1-2), 49-56 (8 pages).

Song, S.; Lopez-Valdivieso, A.; Hernandes-Campos, D. J.; Peng, C.; Monroy- Fernandez, M. G.; Razo-Soto, I., (2006). Arsenic removal from high-arsenic water by enhanced coagulation with ferric ions and coarse calcite. Water Res., 40 (2), 364372 (9 pages).

Weber, W. J.; Morris, J. C., (1963). Kinetics of adsorption on carbon from solution. J. Sanit. Eng. Div. Am. Soc. Civ. Eng., 89 (17), 31-60 (30 pages).

WHO, (1996). Health criteria and other supporting information. In: World Health Organization, Guidelines for drinking-water quality, $2^{\text {nd }}, 2$, Geneva.

\begin{abstract}
AUTHOR (S) BIOSKETCHES
Urík, M., M.Sc., postgraduate student in Nature protection and utilization, Institute of Geology, Faculty of Natural Sciences, Comenius University in Bratislava, Mlynská dolina, 842 15, Bratislava, Slovakia. Email: urik@fns.uniba.sk

Littera, P., M.Sc. postgraduate student in Nature protection and utilization, Institute of Geology, Faculty of Natural Sciences, Comenius University in Bratislava, Mlynská dolina, 842 15, Bratislava, Slovakia. Email: littera@fns.uniba.sk

Ševc, J., Ph.D., Lecturer and researcher, Institute of Geology, Faculty of Natural Sciences, Comenius University in Bratislava, Mlynská dolina, 842 15, Bratislava, Slovakia. Email:sevc@fns.uniba.sk

Kolenčik, M., M.Sc. postgraduate student in Geochemistry, Institute of Geology, Faculty of Natural Sciences, Comenius University in Bratislava, Mlynská dolina, 842 15, Bratislava, Slovakia. Email: marekkolencik@gmail.com

Čerňanský, S., M.Sc., Researcher, Department of Ecosozology and Physiotactics, Faculty of Natural Sciences, Comenius University in Bratislava, Mlynská dolina, 842 15, Bratislava, Slovakia. Email: cernanskys@fns.uniba.sk
\end{abstract}

This article should be referenced as follows:

Urík, M.; Littera, P.; Ševc, J.; Kolenčík, M.; Čerňanský, S., (2009). Removal of arsenic (V) from aqueous solutions using chemically modified sawdust of spruce (Picea abies): Kinetics and isotherm studies. Int. J. Environ. Sci. Tech., 6 (3), 451-456. 